\title{
Effect of Au Thickness on Laser Beam Penetration in Semiconductor Laser Packages
}

\author{
Wood-Hi Cheng, Member, IEEE, Szu-Chun Wang, Yi-Dian Yang, Sien Chi, \\ Maw-Tyan Sheen, and Jao-Hwa Kuang
}

\begin{abstract}
Comprehensive measurements of the dependence of the weld width, penetration depth, and joint strength on the Au coating thickness in laser welding techniques for semiconductor laser packages are presented. The results obtained from the Invar-Invar joints show that the welded joints with thick Au coating exhibit narrower weld width, shallower penetration, and hence less joint strength than those the package joints with thin Au coating. A finite-element method (FEM) has been carried out on the effect of Au thickness on laser beam penetration in Invar-Invar joints. This method has been employed successfully to predict the laser beam penetration in laser welded Au-coated materials that the weld width and the penetration depth are reduced as the Au coating thickness increases. The likely cause for the reduction is the increased thermal conduction of thicker $\mathrm{Au}$ in the welded region. In addition to Au coating, the effect of Ni coating on laser beam penetration is also presented. Detailed knowledge of the effect of Au coating thickness on laser beam penetration is important for the practical design and fabrication of reliable optoelectronic packaging having laser welded Aucoated materials.
\end{abstract}

Index Terms-Au coating, finite-element method, laser welding, optoelectronic packaging.

\section{INTRODUCTION}

$\mathbf{T}$ WO common package styles, which are widely used for laser-based transmitters in lightwave communication systems, are the dual-in-line package (DIP) and butterfly package with fiber pigtails [1]. For high frequency package applications the butterfly style has an advantage due to the shorter wire path of the configuration. The laser welding technique offers significant advantages in construction optoelectronic packages such as semiconductor laser components. This construction method provides strong joints which should improve longterm stability of the package. Manufacturing costs should be reduced because the methods can be applied to high- speed and high-volume production.

When laser welding is applied to semiconductor laser DIP or butterfly packages, it is usually necessary to have mechanical

Manuscript received January 31, 1997; revised June 13, 1997. This work was supported in part by the National Science Council, R.O.C., under Contract NSC 86-2215-E-110-005 and the Telecommunication Laboratories, R.O.C., under Contract TL-86-5103.

W.-H. Cheng and Y.-D. Yang are with the Institute of Electro-Optical Engineering, National Sun Yat-sen University, Kaohsiung, Taiwan, R.O.C.

S.-C. Wang is with the Chunghwa Telecom Laboratories, Yang-Mei, Taoyuan, Taiwan, R.O.C.

$\mathrm{S}$. Chi is with the Institute of Electro-Optical Engineering, National Chiao Tung University, Hsinchu, Taiwan, R.O.C.

M.-T. Sheen and J.-H. Kuang are with the Mechanical Engineering Department, National Sun Yat-sen University, Kaohsiung, Taiwan, R.O.C.

Publisher Item Identifier S 1070-9894(97)07423-9. elements such as substrates, tubes, and clips of house materials to facilitate fiber handling and retention within the package. The thermal expansion of such elements may cause stresses and alignment changes. It is therefore necessary to use housing materials with low coefficient of thermal expansion (CTE) [2], [3]. Invar [4] or Kovar [5], for example, with its very low CTE is frequently used as the housing material for microelectronic and optoelectronic packaging. In this work the Invar with CTE of $1.5 \times 10^{-6} /{ }^{\circ} \mathrm{C}$ is used for study. The Invar alloy [4], which contains approximately $64 \% \mathrm{Fe}$ and $36 \% \mathrm{Ni}$, provides good weldability characteristics for laser welding.

The housing material of Invar is often coated with an $\mathrm{Au}$ thin film to promote good solderability to achieve good chip bonding. However, the laser welding process can be influenced by the thickness of the Au coating on the housing materials. An excess thickness of Au coating on housing materials in laser welding process may cause undesirable reactions which can reduce laser beam penetration [6], [7] or generate defects [8]-[10] in the welded region. The reduction of the laser beam penetration results in less joint strength in the welded region. Both the effect of joint strength reduction and defect formation in the welded sections may affect package reliability. Therefore, for the most practical design and fabrication of reliable optoelectronic packaging, an optimal strategy for the Au coating thickness is necessary to ensure both the highest weld strength and the good solder adhesion on the same housing materials in the laser welding process. Such a design of Au thickness must recognize that an Au coating that is too thick will reduce laser beam penetration and generate defect, and a coating that is too thin will result in poor solderability.

Despite numerous studies on the laser welding technique for large joint applications [11], only limited information is available for optoelectronic joining applications in which joint strength is the prominent issue for package reliability. In this work, we present the experimental measurements and the finite-element method (FEM) to study the dependence of the laser beam penetration on the Au coating thickness in DIP constructions comprised of all Invar materials. The results of this study have led to an important understanding of the requirements for the design of $\mathrm{Au}$ coating thickness of housing materials in semiconductor laser packaging.

The rest of this paper is organized as follows. In this work, Section II will describe the laser welding system, the package construction, and the weld spot measurements. Section III will present the measurements of the weld width, penetration depth, and joint strength without and with Au coatings. Section IV 


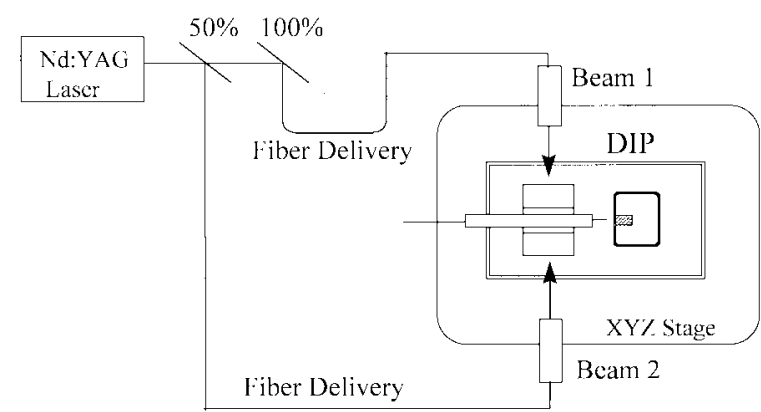

Fig. 1. Schematic diagram of the laser welding system.

will describes the FEM model and Section V will present the results of simulations without and with $\mathrm{Au}$ and Ni coatings. A discussion and brief summary are given in Section VI.

\section{LASER WELDING SYSTEM AND EXPERIMENTAL PROCEDURE}

\section{A. Laser Welding System}

In the process of fabricating a DIP, dual-beam laser welding was used to connect the pigtail fiber assembly to the semiconductor laser. Fig. 1 shows the experimental setup of the laser welding system. The system consisted of a pulsed $\mathrm{Nd}$ : YAG laser and a fiber optic beam-delivery system. The wavelength of Nd : YAG laser was $1.064 \mu \mathrm{m}$. Two laser beams delivered from the $\mathrm{Nd}$ : YAG laser to the workpiece were accurately adjusted with the same energy and with the incident angles of $\left(45^{\circ} \pm 1^{\circ}\right)$. The laser energy required to create the welds was delivered simultaneously through two fibers placed $180^{\circ}$ apart as shown in Fig. 1. Under such a setup, two laser beams were delivered symmetrically around the welded joint. The simultaneous and identical energy delivery may reduce post-weld-shift (PWS) in the two components because the solidification-shrinkage of both welds can compensate each other, resulting in minimized displacement shifts [10], [12], [13]. The $x-y-z$ driving stage was used to align the fiber to laser chip so that the coupled power could be maximized.

Invar materials without and with Au coating were used. A circular spot of average $0.75 \mathrm{~mm}$ in diameter was produced by a well-focused laser pulse on the Invar plate. The diameter of the welded spot decreases as the laser pulse energy decreases. The impinging laser pulse energy for each different Au thickness of Invar plate were scanned by every $1 \mathrm{~J}$. The lowest energy spot was then obtained when the laser pulse was punching through the plate.

\section{B. Package Construction}

The DIP construction consisted of a $1.3 \mu \mathrm{m}$ laser, the Invar housing materials, a TE cooler, and a single-mode fiber as shown in Fig. 2(a). The Invar plate, $u$-channel, and Invar tube of the Invar housing materials with very low CTE were chosen to secure the fiber in alignment with the semiconductor laser in order to minimize the thermal stress and strain developed. Machining accuracy of flatness and finish of Invar housing materials were designed to be less than $10 \mu \mathrm{m}$. In a DIP (a)
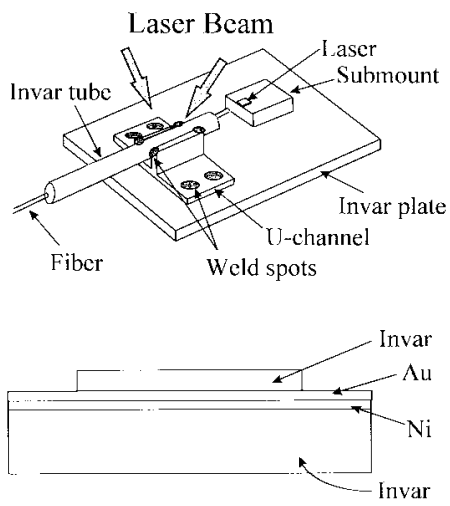

(c)

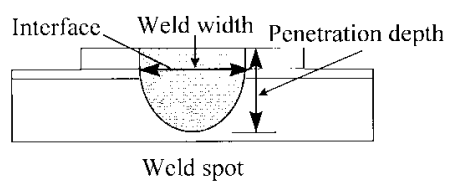

Fig. 2. (a) Top view of a dual-in-line package showing the pigtail fiber to laser connection, (b) Invar plate-to-Invar plate joint, and (c) the penetration depth and weld width of weld spot.

construction, the fiber-to-Invar tube and the submount-to-Invar plate assemblies were solder joints, where the Invar tube-to-u channel and the $u$ channel-to-Invar plate assemblies were weld joints. Both silver-tin and gold-tin solders were employed to form the solder joints. In this study of the laser welding process, both solder joints for good adhesion and weld joints for high strength in the same housing materials were essential for ensuring good reliability in optoelectronic packages.

\section{Weld Spot Measurements}

There were a total of four welded spots on the laser-welded Invar tube-to- $u$-channel or $u$-channel-to-Invar plate joints as shown in Fig. 2(a). To simplify the study of the laser welding process on the DIP, the $u$ channel-to-Invar plate and the Invar tube-to- $u$ channel joints were substituted by the Invar plateto-Invar plate joints as shown in Fig. 2(b). The thicknesses of the upper and lower Invar plates were 0.3 and $1.2 \mathrm{~mm}$, respectively. The thicknesses of $\mathrm{Au}$ plating in the range of $1-5 \mu \mathrm{m}$ were measured by the metallographic microscope. A $4 \mu \mathrm{m} \mathrm{Ni}$ underlayer was used on all Au-plated Invar plates.

Fig. 2(c) shows a laser-welded spot. The penetration depth was measured in the direction of the laser beam, while the weld width was measured in the direction along the contact interface. The laser weldability of the weld width and the penetration depth in the laser welding process for optoelectronic packaging were directly observed using metallographic methods. The standard procedures of the metallographic preparation were the sample sectioning, mounting, grinding and polishing, chemical etching, microscope examination, and measurements [10].

\section{Measurement Results}

\section{A. Joint Strength}

To examine the laser weldability, the joint strength of the welded samples was measured with a push test fixture of 


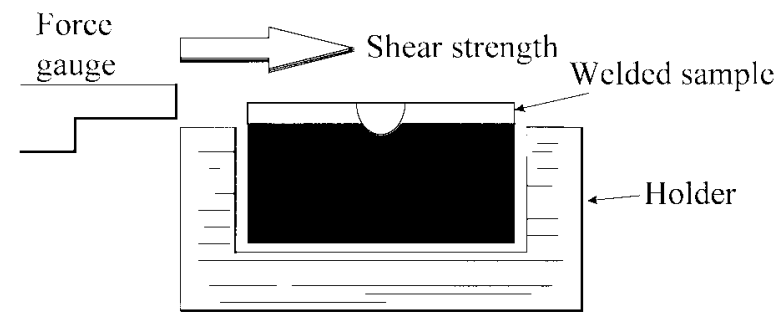

Fig. 3. A push test fixture.

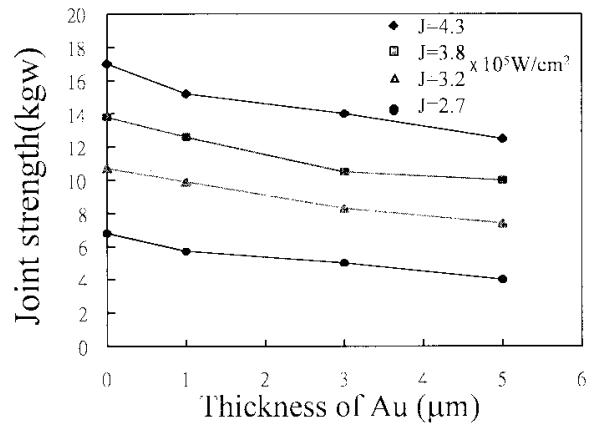

Fig. 4. Joint strength as a function of Au coating thickness for different laser power density.

inhouse design. The fixture consisted of a force gauge and a holder as shown in Fig. 3. Five samples at each welded spot were measured under push test. The joint force in $\mathrm{kgw}$ unit was obtained by measuring the amount required to break the welded sample from the holder.

Fig. 4 shows the measured results of the average joint strength as a function of Au thickness for different laser power densities. The joint strength decreased as the Au thickness increased, but the joint strength increased linearly as the laser power density increased. A Au coating of $5 \mu \mathrm{m}$ thickness was found to reduce the joint strength by about one third of that without Au coating. Fig. 4 indicates that the Au coating thickness has a strong influence on joint strength in the laser welding technique for Invar-Invar packages.

\section{B. Weld Width and Penetration Depth}

Figs. 5 and 6 show the penetration depth and the weld width as a function of Au thickness for different laser power densities. Five samples at each welded spot were measured from metallographic photos. These samples used for the penetration measurements were different from those used for the joint strength measurements because the former required the welded sample to be broken. The penetration depth was measured in the direction of the laser beam, and the weld width was measured in the direction along the joint interface as shown in Fig. 2(c). Figs. 5 and 6 show that the penetration depth and weld width decreased as Au thickness increased. The results of penetration depth and weld width measurements correlated well with the joint strength measurements. The Invar-Invar packages with thick Au coating showed narrower weld width, shallower penetration, and hence, less joint strength than those of the packages with thin Au coating. Figs. 4-6 clearly indicate that the thickness of Au coating on housing material has strong

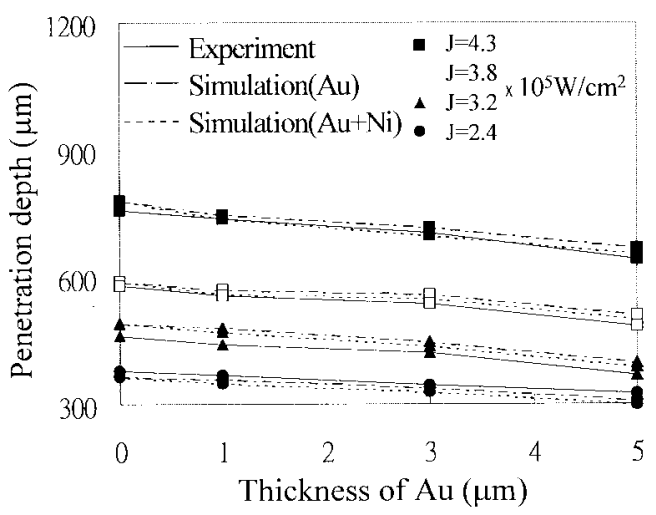

Fig. 5. Measured and simulated penetration depth as a function of Au coating thickness for different laser power density.

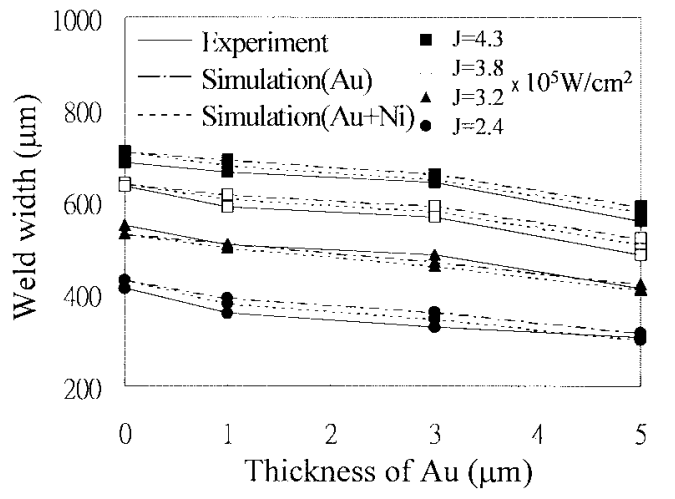

Fig. 6. Measured and simulated weld width as a function of Au coating thickness for different laser power density.

effect on joint strength, weld width, and penetration depth in the laser welding technique for optoelectronic packages. Based on the results of joint strength and laser beam penetration studies in the laser welding process, the optimum thickness of Au coating is found to be $2 \mu \mathrm{m}$ in which both the highest weld strength and good solder adhesion on the same housing materials can be achieved.

\section{Finite Element Method (FEM)}

There were a total of four welded spots on the laser-welded Invar tube-to- $u$-channel or $u$-channel-to-Invar plate joints as shown in Fig. 2(a). Due to the symmetric geometry of the weld pattern, only one weld spot is considered for the FEM simulation. The melting pool of the weld spot formed an elliptical area. The spot areas of the melting pools produced by different laser energies were measured with an optical microscope and were found to range from $0.25-1 \mathrm{~mm}^{2}$. Metallographic analysis was used to determine the depths of the melting pools. These penetration depth ranged from $300-800 \mu \mathrm{m}$. The spot area and melting pool depth were the parameters used for meshment of the FEM simulation.

\section{A. General Finite Element Model}

The numerical simulations of the laser beam penetration in the welded joints were performed using a commercial MARC finite element package. The axial symmetry model 


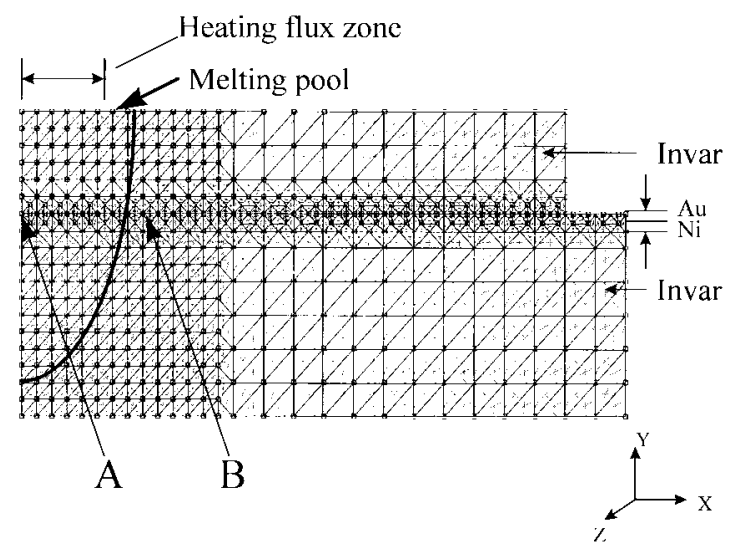

Fig. 7. A representative finite-element method model showing the Au coating, the heating flux zone, and the melting pool.

and temperature variant material properties were used. The thicknesses of the upper and lower Invar plates were 0.3 and $1.2 \mathrm{~mm}$, respectively. Due to symmetry about the centerline, only half the geometry was used as shown in Fig. 2(b). Fig. 7 shows a representative FEM model with $3 \mu$ m thickness of Au coating. The meshes with triangle type elements were created with an automatic mesh generator.

\section{B. Material Characteristics}

The material properties of Invar, $\mathrm{Au}$, and $\mathrm{Ni}$ at room temperature used in the simulation are listed in Table I. In this study, the values of the CTE, Young's modulus, and Poission's ratios are temperature dependent. The temperature dependence of the Young's modulus of Invar, $\mathrm{Au}$, and $\mathrm{Ni}$ materials were assumed to have similar behavior to that of stainless steel (SS) 304L because of the limit of the experimental data available for the Invar, Au, and Ni materials. The Young's modulus as a function of temperature for SS $304 \mathrm{~L}$ was obtained from Metals handbook [4]. The thermal conductivity, specific heat, and mass density values used in the simulation are listed in Table II.

\section{Thermal Load Conditions}

The laser welding process involves a highly focused laser beam being absorbed and conducted into the material being welded, creating a localized molten weld pool [14]. The melting temperatures of Invar, $\mathrm{Au}$, and $\mathrm{Ni}$ in the melting pool were assumed to be $1500{ }^{\circ} \mathrm{C}$. In this study of the FEM model, the boundary conditions were the free edges. The thermal load on the model was the distributed laser power density. Using the laser power density ranging from $2.7-4.3 \times 10^{5} \mathrm{~W} / \mathrm{cm}^{2}$, and the heating time of $3 \mathrm{~ms}$, the temperature profile and profile propagation with respect transient time were simulated.

\section{FEM SIMULATION RESULTS}

\section{A. Weld Width and Penetration Depth}

Fig. 8 shows the simulation results of the temperature profiles for a $3 \mu \mathrm{m}$ thickness of Au coating. A mesh with 925
TABLE I

The Physical Constants of the Young's Modulus, Poission Ratio, and CTE

$\begin{array}{llll} & \text { Invar } & \mathrm{Au} & \mathrm{Ni} \\ \text { Young's modulus }(\mathrm{GPa}) & 37.8 & 78 & 210 \\ \text { Poission ratio } & 0.3 & 0.43 & 0.30 \\ \text { Thermal expansion } & 5.1 & 14.2 & 13.3 \\ \text { coefficient }\left(\mu \mathrm{m} / \mathrm{m}^{\circ} \mathrm{C}\right) & & & \end{array}$

TABLE II

The Material Properties of Thermal Conductivity, Specific Heat, and Mass Density

\begin{tabular}{llll}
\hline & Invar & $\mathrm{Au}$ & $\mathrm{Ni}$ \\
& & & \\
Thermal conductivity $(\mathrm{W} / \mathrm{mK})$ & 16.5 & 317.9 & 90 \\
Specific heat $\left(\mathrm{J} / \mathrm{kg}^{\circ} \mathrm{C}\right)$ & 439.5 & 128 & 452 \\
Mass density $\left(\mathrm{Kg} / \mathrm{m}^{3}\right)$ & 7900 & 19700 & 8900 \\
\hline
\end{tabular}

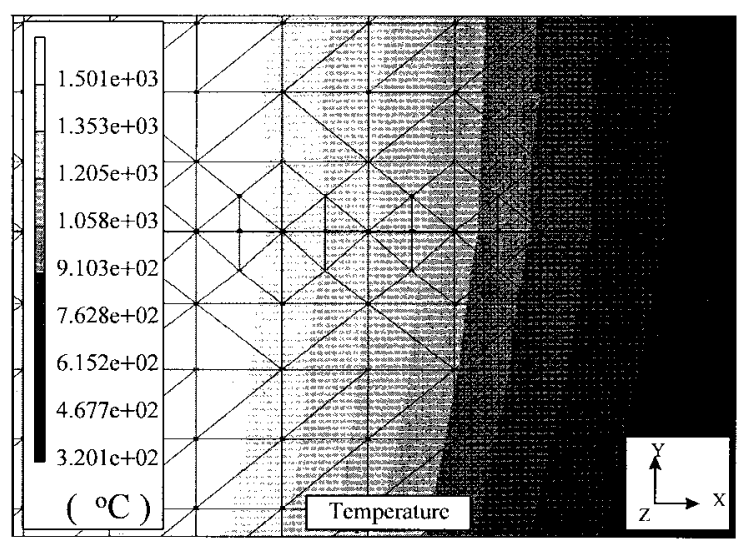

Fig. 8. The temperature profile after heating time of $8 \mathrm{~ms}$ for a $3 \mu \mathrm{m}$ thickness of Au coating.

nodes, 1578 triangle elements for Invar, and 160 triangle elements for Au was employed for the simulation. The different thickness of Au coating of 0,1 , and $5 \mu \mathrm{m}$ were also simulated. The penetration depth and weld width were obtained when the melting pool began solidification at the temperature of 1500 ${ }^{\circ} \mathrm{C}$. The plots of the penetration depth and weld width as a function of $\mathrm{Au}$ thickness for different laser power densities are shown in Figs. 5 and 6, respectively. The results show that the weld width and the penetration depth decreased as the Au coating thickness increased. These numerical simulations are in good agreement with the measured results in which the weld width and the penetration depth were found to be reduced as the Au coating thickness was increased. The results indicate that the FEM is an effective method for predicting the effect of Au coating thickness on laser beam penetration in laser welded $\mathrm{Au}$-coated materials.

\section{B. Temperature Profile Propagation}

Fig. 9 shows the temperature variation as a function of time for different thickness of Au coating. The locations of A and $\mathrm{B}$ indicate the simulation points at the inside and outside 


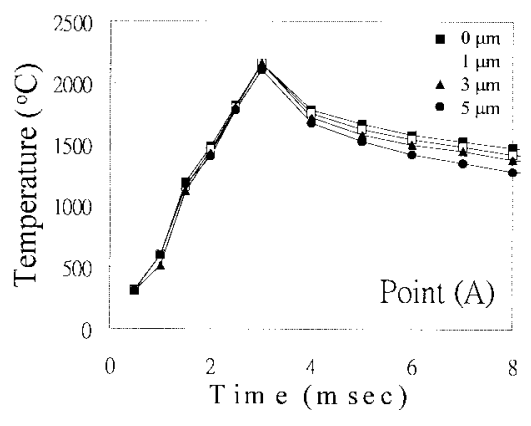

(a)

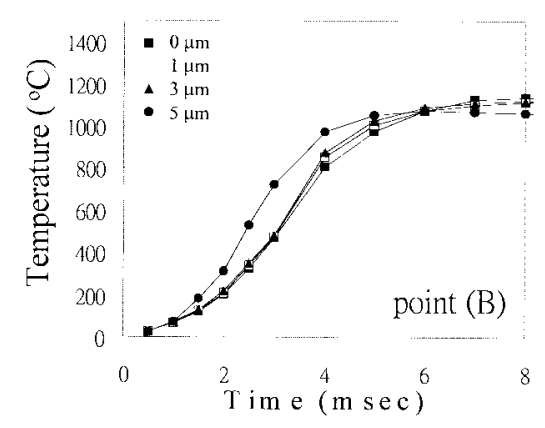

(b)

Fig. 9. The temperature profile variation as a function of time for different thickness of Au coating: (a) point $\mathrm{A}$ at the inside of the melting pool and (b) point $\mathrm{B}$ at the outside of the melting pool.

of the melting pool, respectively. In this study, the thermal loading time was $3 \mathrm{~ms}$. After $3 \mathrm{~ms}$ of heating, the laser beam was turned off and the welded spot began the cooling period. For the same transient time, the temperature change with the thick Au coating increased more quickly then with the thin Au coating during the heating process, while during the cooling process, the temperature change with the thick $\mathrm{Au}$ coating also decreased more quickly then with the thin $\mathrm{Au}$ coating. The temperature profile variation with respect to the $\mathrm{Au}$ coating thickness is shown in Fig. 10. Fig. 10(a) and (b) show the temperature of welded spot at the heating period, while Fig. 10(c) and (d) show the welded spot at the cooling period. The results obtained from both of the heating and cooling periods indicate that at the same position, the welded joints with the thick Au coating exhibited lower temperatures than those with the thin Au coating. The temperature profile and profile propagation of Figs. 9 and 10 clearly indicate that the thermal conduction in welded regions increased as the $\mathrm{Au}$ coating thickness increased. This shows that the Au coating thickness has a significantly strong effect on the temperature profile variations.

Fig. 11 shows the dimension of the melting pool for different thickness of Au coating. The dimension of the melting pool decreased as the Au coating thickness increased. Fig. 11 clearly indicates that the cause for the reduction of the size for the melting pool, and hence the laser beam penetration as the Au thickness increases, is due to the increased thermal conduction of thicker $\mathrm{Au}$ in the welded region as shown in Figs. 9 and 10. This is due to the thermal conductivity of $\mathrm{Au}$ of $317.9 \mathrm{~W} / \mathrm{mK}$ being much higher than the Invar of 16.5 $\mathrm{W} / \mathrm{mK}$. (a)

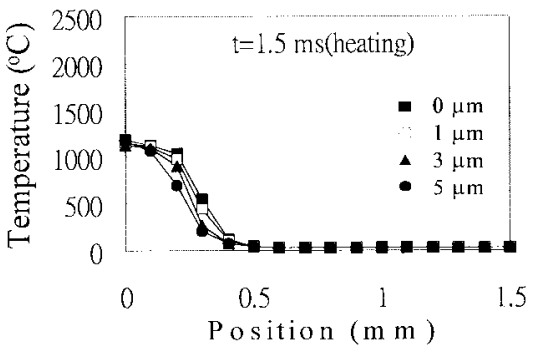

(b)
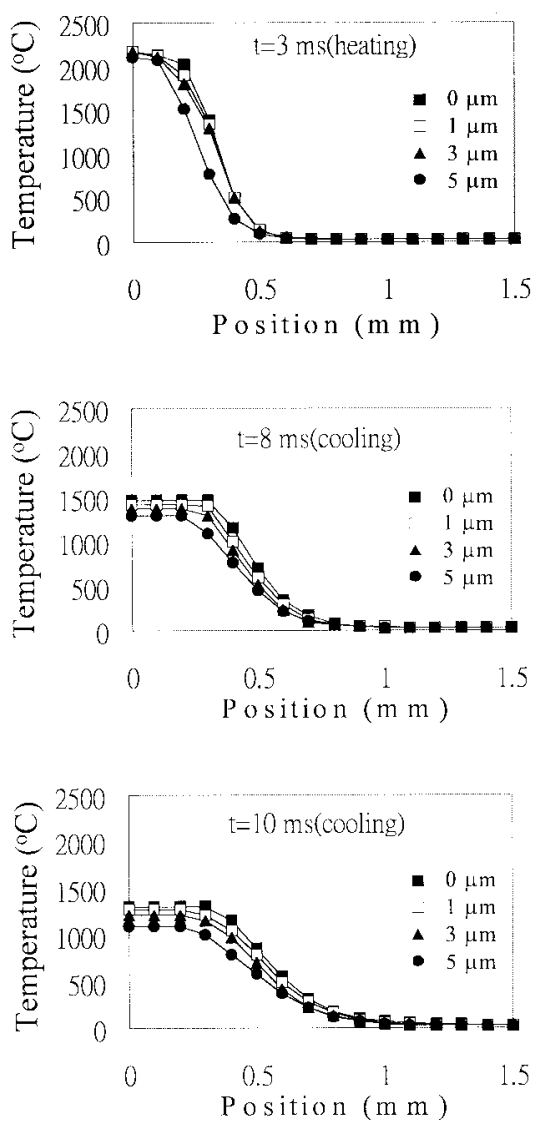

Fig. 10. The temperature profile variation with respect to the Au coating thickness: (a) during heating of $1.5 \mathrm{~ms}$, (b) during heating of $3 \mathrm{~ms}$, (c) after heating of $5 \mathrm{~ms}$, and (d) after heating of $10 \mathrm{~ms}$.

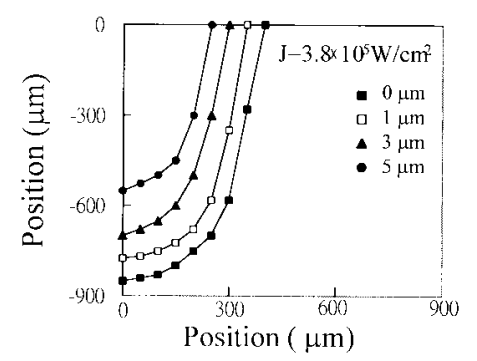

Fig. 11. The dimension of the melting pool for different thickness of $\mathrm{Au}$ coating.

\section{Effect of Ni Coating}

In addition to $\mathrm{Au}$ coating, the effect of $\mathrm{Ni}$ coating on laser beam penetration was also simulated by FEM. In this study 
a $4 \mu \mathrm{m} \mathrm{Ni}$ underlayer on all Au-coated Invar was used for simulation. The simulation results of the penetration depth and the weld width as a function of Au thickness for different laser power densities with a $4 \mu \mathrm{m} \mathrm{Ni}$ underlayer coating are shown in Figs. 5 and 6, respectively. These numerical simulations are also in good agreement with the measured results. The result indicates that the Ni coating has a impact on the laser beam penetration. However, this $4 \mu \mathrm{m}$ Ni underlayer coating may be a secondary effect to contribute to the laser beam penetration in welded materials. This is due to the thermal conductivity of $\mathrm{Ni}$ of $90 \mathrm{~W} / \mathrm{mK}$ being higher than Invar of $16.5 \mathrm{~W} / \mathrm{mK}$, but being lower than $\mathrm{Au}$ of $317.9 \mathrm{~W} / \mathrm{mK}$.

\section{CONCLUSION}

Recently, the thermal conductivity reduction of Ni plating on $\mathrm{Cu}$ and $\mathrm{Al}$ alloy packages in laser welding process has been reported [15]-[17]. With the formation of $\mathrm{Ni} / \mathrm{Cu}$ or $\mathrm{Ni} / \mathrm{Al}$ solid solution in the welded section, the thermal conductivity of $\mathrm{Ni} / \mathrm{Cu}$ or $\mathrm{Ni} / \mathrm{Au}$ is lower than that of pure $\mathrm{Cu}$ or $\mathrm{Al}$. Therefore, the laser beam penetrates the Ni-plated $\mathrm{Cu}$ or $\mathrm{Al}$ more deeply than it does for pure $\mathrm{Cu}$ or Al. A similar effect of the formation of $\mathrm{Au} / \mathrm{Invar}$ solid solution in the welded sections for laser welded Au-plated Invar may therefore be assumed. Detailed measurements of the thermal conductivity of Au/Invar is important and will be pursued in a separate study. Nevertheless, in this study the reduction of laser beam penetration in laser welded Au-plated Invar materials was found.

In summary, we have presented the experimental results and the finite-element calculation for the effect of the Au coating thickness on the laser beam penetration in semiconductor laser packages. The experimental results showed that the welded joints with thick Au coating exhibit narrower weld width, shallower penetration, and hence less joint strength than those package joints with thin Au coating. The numerical simulation was in good agreement with the measured results that the weld width and the penetration depth were found to be reduced as the Au coating thickness was increased. The likely cause for the reduction of the laser beam penetration as the Au thickness increases is due to the increased thermal conduction of thicker $\mathrm{Au}$ in the welded region. This study indicates that the FEM is an effective method for predicting the effect of Au coating thickness on laser beam penetration in laser welded Au-coated materials. The effect of Ni coating on laser beam penetration in laser packages was also simulated successfully by the FEM. Detailed knowledge of the effect of Au coating thickness on the laser-welded Au-coated materials, which gives both the highest weld strength and good solder adhesion, is essential for the practical design and fabrication of reliable optoelectronic packaging.

\section{REFERENCES}

[1] D. S. Alles, "Trends in laser packaging," in Proc. 40th ECTC, 1990, pp. $185-192$.

[2] R. Chanchani and P. M. Hall, "Temperature dependence of thermal expansion of ceramics and metals for electronic packages," IEEE Trans. Comp., Hybrids, Manufact. Technol., vol. 13, pp. 743-750, 1990.
[3] E. Suhir, "Thermally induced stresses in an optical glass fiber soldered into a ferrule," J. Lightwave Techol., vol. 12, no. 10, pp. 1766-1770, 1994.

[4] "Low-expansion alloys," Metals Handbook, 8th ed. Cleveland, OH: ASM, 1973, vol. 8, pp. 266-267.

[5] Kovar Alloy Handbook. Philadelphia, PA: Westinghouse Electric Co. 1971.

[6] S. C. Wang, C. M. Wang, C. Wang, H. L. Chang, S. Chi, Y. K. Tu, C. J. Hwang, W. H. Wang, and W. H. Cheng, "Effect of thin film coating of Au on joint strength in Invar-Invar packages," J. Electron. Mater., vol. 25 , no. 11 , pp. $1797-1800,1996$

[7] S. C. Wang, H. L. Chang, C. Wang, C. M. Wang, J. W. Liaw, M. T. Sheen, Y. C. Sheu, J. H. Kuang, Y. D. Yang, and W. H. Cheng, "Effect of Au coating on laser beam penetration in Invar-to-Invar packages," in Proc. 47th ECTC, 1997, pp. 1272-1276.

[8] R. J. Coyle, P. P. Solan, P. L. Sakach, and X. L. Yeh, "Intergranular embrittlement of laser welds by gold segregation," in Proc. ASM Int., 2nd Conf. Trends Weld. Res., 1989, pp. 661-665.

[9] J. C. Chen, W. T. Chen, S. T. Chang, J. S. Horng, H. H. Lin, M. J. Sun, W. H. Wang, and W. H. Cheng, "The failure mechanisms in semiconductor laser packaging," in CLEO Tech. Dig., pp. 352-353, 1996.

[10] W. H. Cheng, W. H. Wang, and J. C. Chen, "Defect formation mechanisms in laser welding technique for semiconductor laser packaging," IEEE Trans. Comp., Hybrids, Manufact. Technol., vol. 19, pp. 764-769, 1996.

[11] C. Dawes, Laser Welding. Cambridge, U.K.: Woodhead, 1992, chs 3-5.

[12] B. Valk, R. Battig, and O. Anthamatren, "Laser welding for fiber pigtailing with long-term stability and submicron accuracy," Opt. Eng., vol. 34, no. 9, pp. 2675-2682, 1995.

[13] M. K. Song, S. G. Kang, N. H. Hwang, H. T. Lee, S. S. Park, and K. E. Pyun, "Laser weldability analysis of high-speed optical transmission device packaging," IEEE Trans. Comp., Hybrids, Manufact. Technol., vol. 19, pp. 758-763, 1996

[14] T. Miyazaki, "Material removal produced by a high-power-density electron beam," J. Appl. Phys., vol. 48, pp. 3035-3041, 1977.

[15] T. Iikawa, T. Sakai, S. Okamoto, K. Natori, and T. Nagai, "Aluminum alloy package for microwave amplifier," IEEE Trans. Comp., Hybrids, Manufact. Technol., vol. 9, pp. 513-517, 1986.

[16] T. Sakai, S. Okamoto, T. Iikawa, T. Sato, and Z. Henmi, "A new laser hermetic sealing technique for aluminum packages," IEEE Trans. Comp., Hybrids, Manufact. Technol., vol. 10, pp. 433-436, 1987.

[17] K. Shimiz and K. Hashimoto, "Laser welding of copper and copper alloys," Fujitsu Sci. Tech. J., vol. 28, pp. 310- 315, 1992.

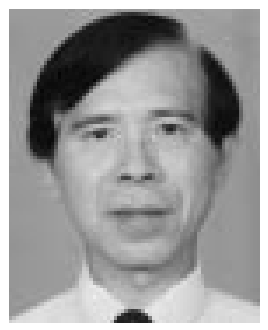

Wood-Hi Cheng (M'95) was born in Changhua, Taiwan, R.O.C., on June 3, 1944. He received the Ph.D. degree in physics from Oklahoma State University, Stillwater, in 1978.

$\mathrm{He}$ is currently a Professor and Director of the Institute of Electro-Optical Engineering at the $\mathrm{Na}$ tional Sun Yat-sen University, Kaoshiung, Taiwan, R.O.C. Previously, from 1991 to 1994, he was an Optoelectronic Packaging Manager at Tacan Corp., Carlsbad, CA. From 1984 to 1991, he was a Principal Design Engineer at Rockwell International, Newbury Park, CA. From 1980 to 1984, he was a Research Engineer at General Optronics, Edison, NJ, and from 1978 to 1980, he was a Research Associate at Telecommunication Laboratories, Taiwan. His research and development activities have been focused on the design and fabrication of high-speed semiconductor lasers for lightwave communications, highly efficient light coupling from lasers and LED's into fibers, fiber couplers, characterization of $I I I-V$ semiconductors materials, and optoelectronic packaging. His current research interests are failure analysis and finite-element method for semiconductor laser packaging, novel material for high density WDM, and high-speed semiconductor lasers for analog and digital lightwave transmission systems. He served as a Consultant for Telecommunication Laboratories, Opto-Electronics and System Laboratories, and Chung-Shan Institute of Science and Technology, Taiwan.

Dr. Cheng is a Member of the Photonics Society of Chinese-Americans. 


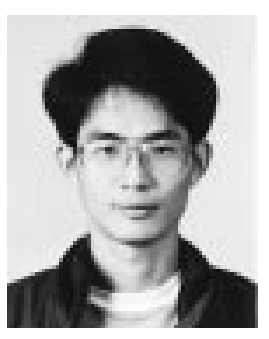

Szu-Chun Wang received the B.S. degree in electrophysics and the M.S. degree in electro-optical engineering, both from National Chiao Tung University, Hsinchu, Taiwan, R.O.C., in 1986 and 1990 respectively, where he is currently pursuing the Ph.D. degree.

He currently works as an Associate Researcher at Chunghwa Telecom Laboratories, Taoyan, Taiwan. Previously, from 1993 to 1995, he was an Optoelectronic Packaging Project Leader at Telecommunication Laboratories, Taoyan. His research interests are optoelectronic packaging for telecommunication applications, including the use of packaging for high-speed and low-cost lightwave systems.

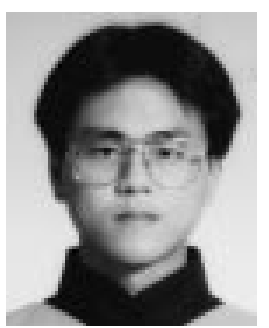

Yi-Dian Yang received the B.S. degree in physics and the M.S. degree in electro-optical engineering, both from National Sun Yat-sen University, Kaoshiung, Taiwan, R.O.C, in 1995 and 1997, respectively. He currently serves in the Army, Taiwan.

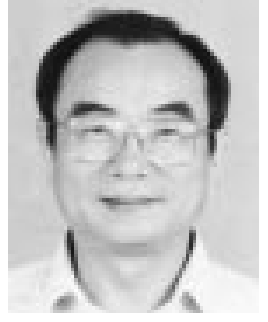

Sien Chi received the B.S.E.E. degree from National Taiwan University, Taipei, Taiwan, R.O.C., in 1959, the M.S.E.E. degree from the National Chiao Tung University, Hsinchu, Taiwan, in 1961, and the Ph.D. degree in electrophysics from the Polytechnic Institute of Brooklyn, Brooklyn, NY, in 1971.

In 1971, he joined the faculty of National Chiao

Tung University, Hsinchu, where he is currently a Professor of electro-optical engineering. From 1972 to 1973 , he was the Chairman of the Department of Electrophysics. From 1973 to 1977, he was the Director of the Institute of Electronics. From 1977 to 1978, he was a Resident Visitor at Bell Laboratories, Holmdel, NJ. From 1988 to 1990, he was the Director of the Institute of electro-optical engineering. His research interests are in the area of optical solitons, optical fiber amplifiers, and optoelectronic packaging.

Dr. Chi is a Fellow of the Optical Society of America and the Photonics Society of Chinese-Americans. He is a recipient of the 1993 Distinguished Research Award, National Science Council, R.O.C.

Maw-Tyan Sheen, photograph and biography not available at the time of publication.

Jao-Hwa Kuang, photograph and biography not available at the time of publication. 